\title{
One year's activity and outcome data from an ambulatory cardiology unit
}

\author{
Authors: Jill Byrne ${ }^{A}$ and Damian McCall ${ }^{B}$
}

\begin{abstract}
In 2015, the Belfast Trust piloted an ambulatory cardiology unit (ACU). The ethos of the ACU was to reduce pressure on the Emergency Department by providing a unit where rapid evaluation, treatment and follow-up could be provided by the cardiology team and, at the same time, reduce inpatient admissions to cardiology beds. The service proved effective in reducing admissions to cardiology beds by $13.5 \%$ over a 1 -year period, while patient outcomes at 30 days and 6 months demonstrated that the service is safe, with only $1.7 \%$ of patients readmitted at 30 days and 6 months with the same or a related complaint. The principles of ACU could be adopted by many other specialities.
\end{abstract}

KEYWORDS: Ambulatory emergency care, ambulatory care, emergency care, outcomes

\section{Background}

A recent report from the King's Fund ${ }^{1}$ on the status of emergency care in England shows that not only are more patients attending the emergency department (ED), but that admissions to inpatient beds from the ED have also increased. Rising admission rates leads to 'exit block' from the ED, with fewer inpatient beds available for further admissions. This can lead to overcrowding in the $E D$, with a knock-on effect on waiting times, contributing to an unsafe environment. ${ }^{2}$ Figures show that, over the past 5 years, attendances to the Royal Victoria Hospital ED have increased by 13,000, from 79,420 in 2012 to 92,245 in 2016.

The Keogh Report ${ }^{3}$ focused on transforming care, improving access to diagnostics and finding new ways of delivering services, suggesting that there should be less emphasis on beds and buildings, and more emphasis on patients having the right care, at the right time, from the right person. Recent developments in health service reform in Northern Ireland have seen the publication of the Bengoa report, Systems, Not Structures, ${ }^{4}$ which clearly states that 'Something very different has to happen at the delivery of care level.' Maintenance of existing services is not sustainable, and new methods of managing healthcare needs

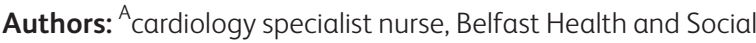
Care Trust, Belfast, UK; ${ }^{\mathrm{B}}$ consultant cardiologist, Belfast Health and Social Care Trust, Belfast, UK must be developed and evaluated. This paper reports on the experience of an ambulatory cardiology unit (ACU) during its first year of service.

\section{The ambulatory cardiology unit}

In 2015, the Belfast Trust piloted an ACU. This was based within a cardiology ward with access to the cardiac investigation department, but on a site remote from the ED. The unit comprised a four-bedded bay, within an interventional cardiology ward, staffed by one cardiologist and two cardiology nurse practitioners. Both nurse practitioners were moved to the ACU from other areas, one to scope and set up the service, with the other team member joining as the workload began to build. The aim was to see 10 patients per day. Opening times were from $9 \mathrm{am}$ to $5 \mathrm{pm}$, Monday to Friday.

The ethos of the ACU was to reduce pressure on the ED by providing a unit where rapid evaluation, treatment and follow-up could be provided by the cardiology team and, at the same time, reduce inpatient admissions to cardiology beds. Selected groups of patients who might traditionally have been admitted to hospital, could be seen quickly and managed within the ACU, with access to specialist cardiology resources and investigations, avoiding hospital admission. In setting up this service, collaboration with the ED was key in ensuring the success of the project, not least because the ACU was not co-located with the ED, but on a different site. This required the ED to be confident that the patients would be seen in a timely manner, and represented a shift in practice from referral to the on-call cardiology team for admission, to a rapid ACU review, which could be a few days after their initial presentation. The existence of such a service would allow the ED team to rapidly assess and stream the patient to early specialist assessment, while reducing exit block from the ED and preserving inpatient beds for the sickest patients.

A 3-month preparation phase allowed for hospital systems to be interrogated and to identify patients who were formally admitted to cardiology inpatient beds, but who had a length of stay of 0 or 1 day in hospital. These were the conditions targeted as suitable for referral from the ED to the ACU, with the agreement of the ED. Conditions initially identified as suitable for ACU referral included atrial fibrillation (AF) and other atrial arrhythmias, new or worsening heart failure, and syncope thought to have a cardiac cause. In addition, pericarditis and palpitations with presyncope/ syncope or an abnormal electrocardiogram (ECG), known structural heart disease, or a family history of inherited disease were also included. Information sessions were delivered to ED 
staff and the cardiology team to publicise the service and to detail referral criteria and processes.

Here, we report on activity over the first year of the service. Monthly data on inpatient admissions from the ED were analysed to assess the overall reduction in admissions and also by target condition. We report on patient outcomes at 30 days and 6 months in terms of presentation to unscheduled care facilities, admission to hospital and mortality.

\section{Methods}

To measure the impact of the new service, a pre-post design was used for comparison with admission rates for 1 year after the initiation of the ACU. This was compared with the number of admissions from the ED to inpatient beds for the same time period of the preceding year, when no alternatives to inpatient admission or routine outpatient referral were available. This information was gathered from the ED software system. To ensure that all the patients had an admission under cardiology, all patients had to be followed up by health and care number to ascertain the discharge diagnosis and consultant responsible for their care. All outliers from other specialties were removed from the data.

Baseline measurements showed that there were 1,651 cardiology admissions to cardiology inpatient beds from the ED in the time period September 2014 - August 2015. The number of patients presenting to the ED in the same time period was 86,520 . The aim was to open the ACU, then measure to assess whether there was any reduction in overall admissions, particularly in the groups targeted as suitable for the ACU. This would allow for adjustments in practice and streamlining of referral criteria. A database was maintained to measure activity.

\section{Results}

\section{Activity}

During its first year, the ACU saw 946 new patients, of whom 722 were referred from the ED. Other sources of referral were the inpatient stream $(n=40)$, to facilitate earlier discharge with planned follow-up, and from the urgent outpatient stream $(n=122)$. Some sources of referral were not anticipated, such as patients attending for routine appointments referred from cardiac investigations and from the pacemaker clinic with left ventricular systolic dysfunction (LVSD) or new-onset AF $(n=51)$.

There was a variety of conditions seen (Fig 1), with those with $A F$ being the largest patient group referred $(n=270)$. In addition, there were 203 referrals with palpitations, 191 with syncope, 127 with heart failure and 27 with pericarditis. Besides these referrals, there were 128 others; a variety of patients with valvular disease, cardiomyopathies, ventricular arrhythmias and inherited disease. The mean age for patients referred to the ACU was 55.2 years.

Of these new patients, 169 were referred on for either specialist opinion or onward referral to the heart failure team. There were 23 patients admitted to a cardiology bed directly from the ACU on the initial or review appointment $(2.2 \%)$, with a further two patients admitted following unscheduled review (total $2.4 \%$ ).

There were 698 reviews carried out within the first year, bringing the total number of patient episodes to 1,644 .

\section{Reduction in admissions}

Results showed an overall decrease in cardiology admissions of $13.5 \%$ (Fig 2). Admission rates to inpatient cardiology beds from the ED fell from 1,651 (out of 86,520 ED attendances over the same time period) to 1,428 (out of 93,221 ED attendances over the same time period). There was an overall increase in ED attendances of 6,701 over the September 2015 - August 2016 period. If these patients had all been admitted to hospital for one night, this would have cost the trust $£ 111,500$. In addition, there was a reduction in admissions in patients with conditions targeted by the ACU. Admissions with AF and other atrial arrhythmias reduced by $24 \%$, and admissions with syncope by $29 \%$. There was a reduction of $45 \%$ in admissions with pericarditis. There was no reduction in admissions with heart failure or palpitations.

\section{Patient outcomes}

We followed patients up to assess whether there was an unscheduled care attendance, an emergency admission or mortality. Eight patients were lost to follow-up because they were not registered with a GP in Northern Ireland. During the first year, 23 patients were admitted to cardiology directly from the ACU $(2.4 \%)$

\section{0-day outcomes}

Unscheduled care presentations. In total, 60 patients re-presented within 30 days for unscheduled care $(6.3 \%$ of all patients seen; Table 1), 16 patients returned with further symptoms related to their initial attendance $(1.7 \%)$, with $50 \%$ of these returning to the ACU for unscheduled care.

Admissions. Overall, 25 patients were admitted to hospital from the $\operatorname{ED~(~} 41.6 \%$ of reattenders, $2.6 \%$ of all patients seen), but

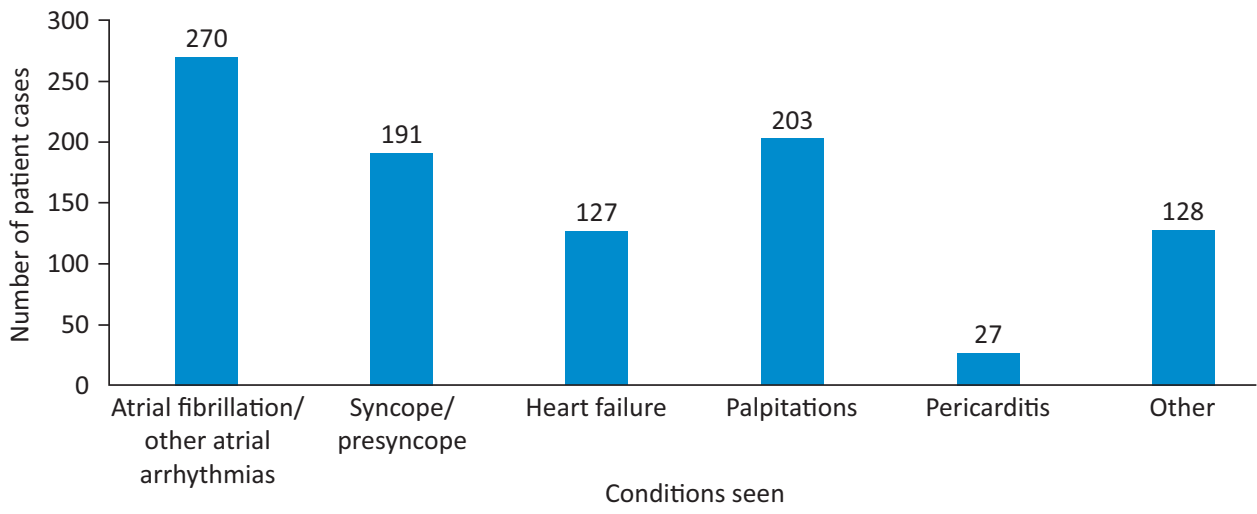

Conditions seen
Fig 1. Conditions seen in the ambulatory cardiology unit over the first year. 
Fig 2. Reduction of admissions by month over 1 year.

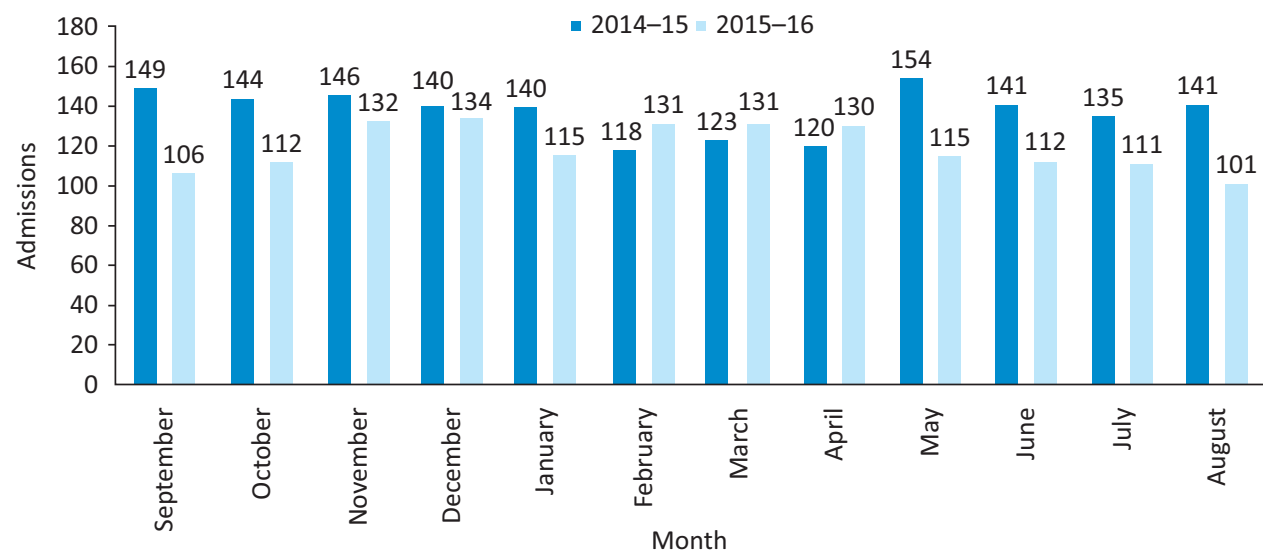

only four of these were admitted for the same reason that they attended the $\operatorname{ACU}(0.4 \%$ of all patients seen).

Mortality. There were four deaths: three from malignancy and one from non-ST elevation myocardial infarction. This patient had a significant cardiac history and was originally referred to the service with heart failure. Mortality accounts for $0.4 \%$ of all patients seen in the ACU. None of these patients died from the original cause for referral to the ACU.

\section{6-month outcomes}

Unscheduled care presentations. In total, 217 patients presented for unscheduled care $(28 \%)$, but only 42 of these patients $(4.4 \%)$ presented with the same complaint as they had originally presented to ACU (Table 2). There were 15 people with atrial arrhythmias (mean age 50 years), whereas 13 people presented with heart failure (mean age 72 years) and 14 represented with palpitations (mean age 54 years).

Admissions. There were 65 admissions (6.8\% of all patients seen). However, only 12 patients were admitted with the same presenting complaint: two were admitted from the ACU and 10 from the ED. This equates to $5.5 \%$ of unscheduled reattenders at 6 months and $1.3 \%$ of all patients seen.

Mortality. There were 12 deaths, representing $1.3 \%$ of all patients seen. Two patients died from end-stage heart failure, two from community-acquired pneumonia, one from a cardiovascular accident, one from cancer and six from sudden cardiac death. The mean age of this group was 74.8 years and included patients with known significant cardiac disease already receiving maximal therapy.

All of the patients with sudden cardiac death had significant co-morbidities, including severe valvular disease, pulmonary hypertension, renal disease or heart failure. The mean age of this group of six was 76.6 years. Only $0.2 \%$ of all patients seen died from the same condition they were referred to the ACU with (heart failure).

\section{Discussion}

This small service, with one doctor and two nurses, was associated with a reduction in admissions to cardiology beds by $13.5 \%$ over a 1 -year period, in the context of increasing attendances to the ED (86,520 in the 2014-2015 period and 93,221 in the 2015-2016 period). This compares favourably with figures from Derriford Hospital, which demonstrated a $7 \%$ conversion from inpatient to outpatient care over their first 6 months of service. ${ }^{5}$ In addition, several of the conditions targeted by the ACU have shown significant reduction in admissions; $\mathrm{AF}$ and other atrial arrhythmias by $24 \%$, syncope by $29 \%$ and pericarditis by $45 \%$. Only $2.4 \%$ of patients were admitted from the ACU during its first year, with $97.6 \%$ of patients being discharged to review or early investigation. In financial terms, the reduction in admissions of 223 patients over 1 year equates to a saving of $£ 111,500$ if these patients had been admitted to a cardiology bed for 1 night, and had no extra investigations. To give an example of cost reduction for patients with $A F, 54$ admissions were saved, giving a minimum cost saving of $£ 27,000$ if no additional tests were offered. In comparison, care in the ACU will cost one tenth of a programmed activity ( $£ 50$ ) and 1.5 hours of a band 7 nurse's time ( $£ 30$ ). There are no other nursing or healthcare assistant costs currently in the ACU, and these beds are not used by any other team. Therefore, it would cost $£ 4,320$ to see the same 54 patients in the ACU rather than in the $E D$, a cost saving of $£ 22,770$ or $84 \%$.

\begin{tabular}{|c|c|c|c|c|c|c|c|}
\hline $\begin{array}{l}\text { Number of patients } \\
\text { seeking unscheduled } \\
\text { care }\end{array}$ & $\begin{array}{l}\text { Number of } \\
\text { patients } \\
\text { re-presenting } \\
\text { to ACU }\end{array}$ & $\begin{array}{l}\text { Number of } \\
\text { unscheduled } \\
\text { reattenders } \\
\text { admitted } \\
\text { from ACU }\end{array}$ & $\begin{array}{l}\text { Number of } \\
\text { patients } \\
\text { presenting } \\
\text { to ED }\end{array}$ & $\begin{array}{l}\text { Admissions } \\
\text { from ED }\end{array}$ & $\begin{array}{l}\text { Admissions from } \\
\text { ED with the } \\
\text { same presenting } \\
\text { complaint as } \\
\text { seen in ACU }\end{array}$ & $\begin{array}{l}\text { Mortality } \\
\text { (all-cause) }\end{array}$ & $\begin{array}{l}\text { Mortality } \\
\text { from same } \\
\text { complaint } \\
\text { as referred } \\
\text { to ACU }\end{array}$ \\
\hline 60 & 8 & 0 & 52 & 25 & 4 & 4 & 0 \\
\hline $\begin{array}{l}\text { Percentage of } \\
\text { unscheduled reattenders }\end{array}$ & $13.3 \%$ & $0 \%$ & $86.7 \%$ & $41.6 \%$ & $6.6 \%$ & $6.6 \%$ & $0 \%$ \\
\hline $\begin{array}{l}\text { Percentage of total } \\
\text { patients seen }\end{array}$ & $0.8 \%$ & $0 \%$ & $5.5 \%$ & $2.6 \%$ & $0.4 \%$ & $0.4 \%$ & $0 \%$ \\
\hline
\end{tabular}


Table 2. 6-month outcomes

$\begin{array}{llllllll}\begin{array}{l}\text { Number of patients } \\ \text { seeking unscheduled } \\ \text { care }\end{array} & \begin{array}{l}\text { Number of } \\ \text { patients } \\ \text { re-presenting } \\ \text { to ACU }\end{array} & \begin{array}{l}\text { Number of } \\ \text { unscheduled } \\ \text { reattenders } \\ \text { admitted } \\ \text { from ACU }\end{array} & \begin{array}{l}\text { Number of } \\ \text { patients } \\ \text { presenting } \\ \text { to ED }\end{array} & \begin{array}{l}\text { Admissions } \\ \text { from ED }\end{array} & \begin{array}{l}\text { Admissions } \\ \text { from ED with } \\ \text { same presenting } \\ \text { complaint as } \\ \text { seen in ACU }\end{array} & \begin{array}{l}\text { Mortality } \\ \text { (all- } \\ \text { cause) }\end{array} & \begin{array}{l}\text { Mortality } \\ \text { from same } \\ \text { complaint } \\ \text { as referred } \\ \text { to ACU }\end{array} \\ \begin{array}{l}217 \\ \begin{array}{l}\text { Percentage of } \\ \text { unscheduled re-attenders }\end{array}\end{array} & 21 & 2 & 196 & 65 & 10 & 12 & 2 \\ \begin{array}{l}\text { Percentage of total } \\ \text { patients seen }\end{array} & 2.6 \% & 0.9 \% & 90.4 \% & 30 \% & 4.6 \% & 5.5 \% & 0.9 \% \\ \end{array}$

Patient outcomes at 30 days and 6 months demonstrate that the service is safe. Only $1.7 \%(n=16)$ of all patients seen $(n=946)$ were admitted to hospital with the same condition that had resulted in referral to the ACU. There were 16 deaths $(1.7 \%$ of all patients seen), but only two were related to the reason for the referral to the $\mathrm{ACU}(0.2 \%)$.

\section{Benefits and limitations}

There might be an argument that a unit that aspires to deliver ambulatory emergency care should be co-located with the ED. This would allow for decision making on the day the patient arrives to the ED and might be more effective in reducing admissions that are thought to be borderline. This was an option that our team did not have in terms of space or funding at the time the unit was set up. The ACU has not been funded and, therefore, currently does not have access to extra support; thus, we are constrained in terms of the numbers we can accept.

However, the ACU is adjacent to the cardiac investigations department, which is advantageous to the service. We have been able to demonstrate that there is a requirement for three echocardiography slots per day, which helps aid speedier diagnosis and guide management. We also have access to one Holter monitor per day. In addition, we have provided a service for cardiac investigations staff to refer patients who have attended for routine echocardiography or Holter monitoring and subsequently been found to have atrial or ventricular arrhythmias or LVSD. Access to equivalent cardiac investigations would need to be negotiated if the service was to co-locate with the ED, along with reduced access to patients from the outpatient stream to accommodate seeing patients from the ED on the same day.

Access to the service is an issue that the team always needs to monitor closely. Given that we are not co-located with the $E D$, it can take several days before the patient is seen. We have developed a triage system and aim to see those triaged as urgent within 3 days. Currently, referral criteria are being reviewed.

We have not yet analysed the effect of the service on the outpatient cohort. However, we do accept significant numbers of urgent outpatient referrals to the ACU. Currently, the target time to be seen by a cardiologist for a referral triaged as urgent is 6 weeks. If the patient is triaged as urgent and referred to the ACU, we will try to see the patient within a few days and might be able to provide echocardiography or exercise stress test (EST) on the same day, or alternatively, a facilitated slot within a few days. This would not be possible if the patient attended the outpatient clinic. Clearly, being seen more rapidly is beneficial in expediting diagnosis and management plans, and also reduces waiting time and associated anxiety for the patient.

\section{Conclusion}

The principles of the ACU could be adopted by many other specialties. With careful and thoughtful triage, it is possible to see patients quickly even if remote from the ED. Our unit has demonstrated that it has been possible to reduce admissions to cardiology inpatient beds by $13.5 \%$ and has shown a reduction in admissions in the conditions specifically targeted for the ACU. Patient outcomes at 30 days and 6 months indicate that the service is safe, with only $1.7 \%$ of patients readmitted at 30 days and 6 months with the same or a related complaint. In addition, users feel the service is accessible and an alternative to ED attendance, with $50 \%$ of patients who sought unscheduled care for the same or a related complaint accessing the ACU rather than the ED.

Although this is a very small service, it has had a positive impact and demonstrates an alternative way of working. In the current climate, where ministers and clinicians agree that current methods of managing emergency care are unsustainable, our service represents a model that could be implemented by other specialties.

\section{References}

1 Murray R, Jabbal J, Thompson ] et al. Quarterly Monitoring Report 21. The King's Fund, 2016. http://qmr.kingsfund.org.uk/2016/20/ data\#/bf325726-550b-49cc-9628-f6769439413b [Accessed 30 October 2016].

2 McCarthy ML. Overcrowding in emergency departments and adverse outcomes. BMJ 2011;342:d2830.

3 NHS England. High quality care for all, now and for future generations: Transforming urgent and emergency care services in England. The Evidence Base from the Urgent and Emergency Care Review. NHS England, 2013. https://www.england.nhs.uk/wp-content/ uploads/2013/06/urg-emerg-care-ev-bse.pdf [Accessed 30 October 2016].

4 Expert Panel Report. Systems, not Structures; Changing health and social care. Northern Ireland: DoH, 2016. https://www.health-ni.gov. uk/sites/default/files/publications/health/expert-panel-full-report.pdf [Accessed 29 October 2016].

5 Carter A. The ambulatory care unit at Derriford Hospital. Clin Med 2014:14:250-4.

Address for correspondence: Mrs Jill Byrne, c/o Ambulatory Cardiology Unit / 9 South, Belfast City Hospital, 51 Lisburn

Road, Belfast BT9 7AB, UK.

Email: jill.byrne@belfasttrust.hscni.net 